\title{
Electronic nicotine delivery systems: emerging science foundation for policy
}

\author{
J E Henningfield, ${ }^{1}$ G S Zaatari ${ }^{2}$
}

Since they were first marketed in China in 2004, electronic nicotine delivery systems (ENDS) have spread globally like wildfire. Their proponents, who refer to the products as "electronic cigarettes" or "E-cigs", argue that by delivering nicotine to the lung, they are more effective and acceptable than nicotine replacement medicines, and should be readily available as cigarette substitutes. An internet search using terms such as "electronic cigarette" reveals that the products vary widely in form, names, and nicotine delivery claims and health claims. Flavours include "tobacco" as well as cherry and other candy-like flavours banned for use in cigarettes in the USA ${ }^{1}$ and recommended for banning by the World Health Organization (WHO). ${ }^{2}$ ENDS marketers claim benefits: "cancer causing chemicals found in tobacco cigarettes are not found in electronic cigarettes", "not any toxins", "no first or second hand smoke", "tobacco-like taste and flavors", "won't stain teeth or damage skin", "increase productivity and promote the potential health benefits", "its [emissions are] simply water vapor" and "quit smoking". $3-5$

Many public health authorities caution that the risks and benefits of ENDS have not been adequately studied, that they may not deliver nicotine as claimed and may deliver more toxicants than claimed. There is also concern that ENDS may undermine smoking prevention, cessation and clean air laws. ${ }^{67}$ Some countries have banned ENDS until they are adequately studied (eg, Brazil, Canada, Uruguay, Singapore, Turkey). ${ }^{7}$

The foregoing has occurred in virtual absence of published data on the contents, emissions and effects of the products. For medicines, and even for foods with health

\footnotetext{
'Department of Psychiatry and Behavioral Sciences, Johns Hopkins University School of Medicine, Baltimore, Maryland, USA; ${ }^{2}$ Department of Pathology and Laboratory Medicine, American University of Beirut, Beirut, Lebanon

Correspondence to Jack E Henningfield, Research and Health Policy, Pinney Associates, 3 Bethesda Metro Center, Suite 1400, Bethesda, MD 20814, USA; jhenning@pinneyassociates.com
}

claims, manufacturers must conduct studies of safety and efficacy. Little verifiable data support ENDS promotion-and some implied claims are profound: "you can keep smoking with little or no risk to yourself or to those exposed to the second hand emissions". Eventually, laboratories such as those affiliated with The Tobacco Laboratory Network of $\mathrm{WHO}^{8}$ might be able to assess such products; however, the primary responsibility for testing should be the manufacturers'.

Initial data reinforce concerns about ENDS. The US Food and Drug Administration (FDA) conducted preliminary tests of several ENDS models, documenting widely varying levels of nicotine, carcinogens and diethylene glycol, which it noted "is toxic to humans". "The FDA concluded that "quality control processes used to manufacture these products are inconsistent or non-existent" because of variability in contents and emissions. ${ }^{9}$

Tobacco Control has published two peerreviewed studies of ENDS nicotine delivery in humans, one in the last issue and one in this issue. ${ }^{10} 11$ One study ${ }^{11}$ was supported by a major ENDS marketer. The two studies ${ }^{1011}$ provide preliminary data on nicotine absorption and craving relief by several ENDS products. Two limitations of the studies are worthy of special note. First, there are hundreds of brands and models of ENDS, with diverse claims implying unique modes of operation, contents and widely varying nicotine, suggesting potential differences from those tested to date. Second, these shortterm laboratory studies offer little basis for assessing the safety of ENDS as they would actually be used, which could involve hundreds of puffs per day for many years with puffing parameters varying widely.

With the foregoing limitations in mind, the studies were consistent in finding that nicotine absorption did not mimic cigarettes. Eissenberg ${ }^{10}$ found no significant increase in plasma nicotine by either of two product brands. Bullen et a ${ }^{11}$ documented somewhat higher nicotine levels than Eissenberg, but these were far lower than those produced by cigarette smoking, and lower than those typically produced by nicotine replacement medicines for smoking cessation. ${ }^{12}$ Bullen et al did not find significant relief of tobacco withdrawal, but both investigators found some degree of craving relief.

The slow onsetting and low plasma levels do not rule out some degree of lung exposure, but they are not consistent with the lung deliveries advertised at least initially by their marketers. Lung deposition can vary as a function of factors including nicotine concentration in the emissions, particle characteristics and how products are used, and thus might differ with other products and conditions. ${ }^{13}$ To better understand the actual sites of deposition of nicotine and other substances, thorough pharmacokinetics and imaging studies might be required, such as the studies that were conducted with the medicinal nicotine inhaler, leading to the conclusion that less than $5 \%$ of its nicotine inhaled actually reached the lung. ${ }^{14}$ Determining the deposition of ENDS emissions has implications for safety, efficacy and addiction potential because the addictive and other physiological effects of nicotine and lung toxicants such as propylene glycol may be increased by deeper lung penetration. Addiction potential ("abuse liability") should be directly assessed, as for other nicotine-delivering products. ${ }^{15-17}$

ENDS that deliver very low levels of nicotine may pose effective starter products for non-tobacco users. Self-administering nicotine by puffing on ENDS could initiate a nicotine graduation process (as happened in the USA with oral smokeless tobacco industry-termed "starter" products). ${ }^{18}$ Such risks might be mitigated and monitored by a regulatory approach termed risk management, as increasingly required by regulatory authorities such as the FDA, European Medicines Authority and Health Canada. ${ }^{19}$

An additional complication is that ENDS might produce substantially higher deliveries if they are "spiked" with nicotine liquid ("juice") available for refilling their cartridges (eg, Totally WickedELiquid Smoke Juice). ${ }^{20}$ ENDS refill products raise many of the same safety and effectiveness issues as ENDS. A cursory review of such products on the Internet revealed a broad range of refill products, claims and even warnings, with some admitting carcinogens and the possibility of nicotine poisoning (some appear to contain sufficient nicotine to kill many 
persons even if simply spilled on the skin). It would seem that where the nicotine is intended for human consumption, it should be subject to the same regulations for safety and effectiveness as drugs including standards for child-resistant packaging and labelling to minimise risk of poisoning.

The main promise of ENDS, to effectively deliver nicotine so as to substitute for cigarettes, has yet to be demonstrated scientifically for any ENDS. Claims concerning safety to users and by secondhand exposure have yet to be verified. A further complication of safety assessment is that product safety is generally assessed in the context of a benefit-to-risk assessment and the core benefits claimed by ENDS have yet to be demonstrated.

Many other public health issues posed by ENDS were not addressed by the Eissenberg and Bullen et al studies. Smoking bans and clean air advocacy are being hijacked to promote the ENDS marketing claim that the emissions are harmless and should be exempt from restrictions. One ENDS manufacturer states, "These products offer a new opportunity to retailers, bars, restaurants and other businesses, to take advantage of the new smoking-bans". ${ }^{21}$ Such promotion could undermine the benefits of clean air laws in motivating smoking cessation and aiding those who have quit to avoid relapse. Moreover, ENDS produce emissions that can be seen and smelled, and presumably contain nicotine, propylene glycol, and carcinogen-containing tobacco extracts and other substances; however, there has been no systematic study of emissions. $^{67}$ That is why WHO recommends that the use of ENDS in public settings should be subject to the same restrictions as those used to reduce second-hand tobacco smoke exposure under Article 8 of the Framework Convention on Tobacco Control. ${ }^{22}$

ENDS raise many additional questions. Should claims and descriptors such as "no tar", and "no second-hand smoke" be allowed on products whose emissions include carcinogens contained in "tar", potential lung toxicants such as propylene glycol, and nicotine? Should statements such as those describing propylene glycol as a safe food additive be allowed when it is recognised as a toxic substance when inhaled or exposed to the skin ? $^{23}$ Might this category of product be an example of what is needed to augment the smoking cessation armamentarium ? $^{12}$

Despite efforts to regulate ENDS, they continue to be sold globally through the
Internet and in many retail settings in some countries. The judicial ruling preventing the FDA from banning ENDS imports will complicate its efforts to regulate the products; however, the FDA has several regulatory avenues, in addition to its new authority to regulate tobacco products. ${ }^{1} 24$ The studies reported in Tobacco Control, along with the FDA's preliminary assessment, are steps in the direction of an emerging science foundation; however, more research is needed. We recommend surveillance to determine patterns and trends in marketing, sales, use and effects. Healthcare providers should also be notified to be alert for potential respiratory diseases associated with use of ENDS and to report such observations. Manufacturers and retailers must provide evidence to define the appropriate uses of, exposure to and safety of ENDS, and regulatory authorities should confirm the accuracy of this evidence before approving these products for marketing and sale. Meanwhile, this manufacturer-driven (as opposed to public health-driven) experiment in public health will continue to unfold.

Acknowledgements GSZ is chair and JEH is a member of the WHO Study Group on Tobacco Product Regulation (TobReg), and we would like to acknowledge discussions and analysis of ENDS with colleagues at WHO and TobReg; however, this article is not written on behalf of TobReg and the opinions are not necessarily those of WHO.

Competing interests JEH consults on smoking cessation medications to GlaxoSmithKline through Pinney Associates, shares a patent on a nicotine replacement medicine that has not been commercialised, has testified in litigation against the tobacco industry on behalf of the US Department of Justice and other plaintiffs and consults on risk management of potentially addicting drugs.

Contributors Both authors wrote and take full responsibility for this editorial.

Provenance and peer review Commissioned; not externally peer reviewed.

Tobacco Control 2010;19:89-90.

doi:10.1136/tc.2009.035279

\section{REFERENCES}

1. US Food and Drug Administration. Guidance, compliance and regulatory information. 2010. http:// www.fda.gov/TobaccoProducts/default.htm (accessed 1 Feb 2010).

2. World Health Organization. Candy-flavoured tobacco products: research needs and regulatory recommendations. In: The scientific basis of tobacco product regulation: report of a WHO study group. World Health Organization technical report series. Geneva: World Health Organization, 2007:25-42.

3. Anon. Light in the box. 2010. http://www. lightinthebox.com/ (accessed 1 Feb 2010).

4. Anon. NJoy. 2010. http://www.njoy.com laccessed 1 Feb 2010)

5. Anon. Vapure. 2010. http://www.getvapure.com/ default/ (accessed 1 Feb 2010).
6. American Legacy Foundation. E-cigarettes presentation: are E-cigarettes a bridge product to smoking or abstinence? or both? http://www. legacyforhealth.org/3326.aspx laccessed 1 Feb 2010).

7. World Health Organization. TobReg Scientific Recommendation: devices designed for the purpose of nicotine delivery to the respiratory system in which tobacco is not necessary for their operation. In: The scientific basis of tobacco product regulation: report of a WHO Study Group. World Health Organization technical report series. Geneva: World Health Organization, 2009:3-21.

8. Anon. World Health Organization Tobacco Laboratory Network (TobLabNet). http://www.who.int/tobacco/ global interaction/toblabnet/en/ laccessed 1 Feb 2010).

9. United States Food and Drug Administration. Electronic cigarettes. http://www.fda.gov/ NewsEvents/PublicHealthFocus/ucm172906.htm (accessed 1 Feb 2010)

10. Eissenberg T. Electronic "cigarettes": ineffective nicotine delivery and craving suppression after selfadministration. Tob Control 2010;19:8-8.

11. Bullen C, McRobble $\mathrm{H}$, Thornley $\mathrm{S}$, et al. Effect of an electronic nicotine delivery device ("E Cigarette") on desire to smoke and withdrawal, user preferences and nicotine delivery: randomized cross-over trial. Tob Control 2010;19:8-103.

12. Henningfield JE, Shiffman S, Ferguson SG, et al Base, challenges and opportunities for pharmacotherapy. Pharmacol Ther 2009;123:1-16.

13. Wayne FE, Connolly GN, Henningfield JE, et al. Tobacco industry research and efforts to manipulate smoke particle size: implications for product regulation. Nicotine Tob Res 2008;10:613-25.

14. Lunell E, Molander L, Ekberg K, et al. Site of nicotine absorption from a vapour inhaler: comparison with cigarette smoking. Eur J Clin Pharmacol 2000:55:737-41.

15. Carter LP, Stitzer ML, Henningfield JE, et al. Abuse liability assessment of potential reduced exposure products. Cancer Epidemiol Biomarkers Prev 2009; 18:3241-62.

16. Schuster CR, Henningfield JE. Conference on abuse liability assessment of CNS drugs: Introduction. Drug Alcohol Depend 2003;70:S1-4.

17. United States Food and Drug Administration. Guidance for industry: assessment of abuse potential of drugs. Draft Guidance 2010. http://www.fda.gov/downloads/Drugs/ GuidanceComplianceRegulatorylnformation/ Guidances/UCM198650.pdf(accessed 1 Feb 2010).

18. Connolly GN, Winn DM, Hecht SS, et al. The reemergence of smokeless tobacco. N Engl J Med 1986;314:1020-7.

19. Schuster CR, Barthwell AG, Henningfield JE. Introduction to the College on problems of drug dependence special conference on risk management and post-marketing surveillance of CNS drugs. Drug Alcohol Depend 2009;105S:S4-8.

20. Anon. Totally wicked-eliquid smoke juice. http:// www.totallywicked-eliquid.com/ laccessed 1 Feb 2010).

21. Anon. Ruyan. 2010. http://www.ruyan.com.cn/ (accessed 1 Feb 2010)

22. Anon. World Health Organization framework convention on tobacco control. http://www.who.int/ fctc/en/ (accessed 1 Feb 2010)

23. Agency for Toxic Substances and Disease Registry (ATSDR). Toxicological profile for Propylene Glycol. Atlanta, GA: U.S. Department of Health and Human Services, Public Health Service, 1997.

24. Wollscheid KA, Kremzner ME. Electronic cigarettes: safety concerns and regulatory issues. Am J HealthSystem Pharm 2009;66:1740-2. 